\title{
TWINTIGSTE EEUSE LITURGIESE VERNUWING
}

(3)

\section{Waarheen? Vorentoe of agteruit? \\ 6. Saamvatting}

6.1. Ons leef in ' $n$ Laodicensiese tyd (Openb. $3: 14-22$ )

Die leë kerke en die verskeurdheid van die Kerk is in die eerste en laaste plek te wyte aan 'n Laodicensiese louheid van nie warm en ook nie koud wees nie. ,The religious dynamic which has propelled our civilization is found wanting". ${ }^{70}$ As 'n waterstroom swak vloei, dan kan dit niks en niemand meesleur nie en dan raak dit ook alte maklik verdeeld in klein stroompies. Die stukrag en vloei van die kerklike lewe is so flou dat elke lidmaat eintlik 'n belemmering daarin word in plaas van om daardeur saamgesleep te word; verdeeldheid en twis vloei dan alte maklik daaruit voort.

Magtige en indrukwekkende organisasies soos die Wêreldraad van Kerke probeer vandag druk om eenheid en diepte weer te bewerkstellig. Ten opsigte van die liturgie het ons langs mekaar vier strominge aangedui, wat op verskillende maniere daarna streef om die erediens weer op die regte spoor te kry.

Hierdie aksies en bewegings mag valslik die indruk en gevoel bewerkstellig dat die kerklike lewe wêreldwyd of plaaslik tog ryk en welvarend is. Hierteenoor wys Openb. $3: 14$ juis dat waar Christus liefhet tugtig $\mathrm{Hy}$ en roep tot bekering. Hy moet deur sy Woord en Gees weer orde op sake stel, diepte en eenheid bring. Waar ons leef in 'n tyd van eb van die werking van die Heilige Gees, moet ons aan die een kant bid en wag dat God weer 'n hoogty gee, op sy tyd en wyse.80 Aan die ander kant moet ons ons goed rekenskap gegee het van wat aan die gang is in Kerk en wêreld, en dan bid en werk. Die oorwinning is immers seker.

\subsection{Waar vind ons die finale norm, vorentoe of agtertoe? Of albei?}

In die vierstromige pogings tot liturgiese vernuwing skemer daar te midde van louheid en tekortkominge 'n strewe om 'n oplossing te vind. Die ideaal en norm word in die Kerk van die verlede, of in die na-Apostoliese jong kerk of by die Sinode van Dordrecht of in die eskatologiese ideaal gesoek.

Stilweg word soms teruggegaan tot die Ou-Testamentiese kultus of liturgie, bv. die eenmalige offer van Christus word weer herhaal in die Roomse eucharistie...

Hierteenoor moet ons duidelik stel dat ons en die hele kerkgeskiedenis en liturgiese ontwikkeling in sonde ontvang en gebore is. As ons 'n volmaakte norm wil hê, moet ons teruggaan tot voor die sondeval of ons moet 'n volmaakte ideaal om na te streef ná die Voleinding plaas (vgl. Openb. 21 en 22).

Ons moet heeltemal wegkom van alle heidense invloede, wat 
die liturgie laat opgaan in sekere handelinge wat gedoen word om 'n verband tussen God en mens te bewerkstellig sodat die mens dit kan gebruik. Nida praat selfs van 'n gepaganiseerde Christendom, waarby die Christendom maar net 'n ekstra vorm van paganisme geword het. Die radikale verskil tussen die ware Christelike geloof en nie-Christelike geloof gee hy soos volg weer: By eersgenoemde neem God die inisiatief om die gesprek met die mens te open, by laasgenoemde neem die mens die inisiatief om God te soek; die Christelike godsdiens weet die mens se sonde verhinder, kommunikasie - die nie-Christelike godsdiens struikel oor 'n God wat te besig is; die Christelike godsdiens ken as voorwaarde vir kommunikasie berou en versoening - die nie-Christelike stel as voorwaarde gespesialiseerde kennis; die Christen weet God antwoord die mens omdat Hy wil - laasgenoemde dink God antwoord hoofsaak vanweë druk of dwang; eersgenoemde weet God gee alles verniet uit, uit genade - laasgenoemde dink aan 'n aksie tussen God en mens in terme van 'n kontraktuele quid pro quo-reëling; die Christen probeer om God se wil te ken en te gehoorsaam - die nie-Christen probeer om sy wil aan God op te dra.

Ons het die idee dat gespesialiseerde kennis vir kommunikasie nodig is, gekursiveer omdat ons daarin die kerngebrek van verkeerde liturgie in selfs Christelike kerke vind. Daar word geredeneer dat die aanbidder of die liturg die seremonie presies reg moet uitvoer; dan moet God luister. Juis omdat hierdie tegniese korrektheid so delikaat en so magtig is, neem die gewone lidmaat of leek dit nie in hande nie maar word die liturgie oorgelaat aan die "geordende" deskundige, asof sy doen God ooit kan dwing!

\subsection{God is die God wat spreek en openbaar}

God skep deur te sê, deur sy Woord (vgl. Gen. 1 en Joh. 1). Hy pleeg intertrinitêr oorleg (,,Laat Ons ...) voordat Hy die mens skep en Hy openbaar Hom aan die geskape mens deur met hom te praat. Die eerste gemeenskap of kommunikasie tussen God en mens geskied dus woordeliks. God openbaar Homself juis. Selfs as die mens na die sondeval probeer om hom voor God te verberg, soek God hom nogtans op en praat weer met hom. Die eerste ware godsdiens of liturgie in die ruimste sin van die woord, geskied dus woordeliks en persoonlik. So gaan dit voort dwarsdeur die openbaringsgeskiedenis: God praat met sy volk en hulle antwoord Hom. Hierin lê die diepste fondament van die eenheid van belydenis en liturgie (vgl. par. 4).

Helberg onderskei die ,sê" van God (sy woorde) van die heidense woorde met magiese, dwingende, selfs teenoor God, blinde krag. „By Gods skeppingsoptrede is die spreek 'n wilsuiting - van 'n Persoon".83 Ons moet byvoeg: van God-drieënig deur die tweede Persoon, die Woord, deur Wie alles geskape is. In die hemelse liturgieë (vgl. Openb. 4 e.v.) speel die woorde van openbaring steeds die hoofrol en word die boek van Gods raad slegs deur die Lam, die vleesgeworde Woord, oopgemaak. Altyd weer antwoord die 
skepsele en die volk van God daarop met woorde van lofuiting en verheerliking van God. Uiteindelik sal God alles in almal wees (1 Kor. $15: 28$ ). In die nuwe Jerusalem sal daar geen tempel wees nie, „want die Here God, die Almagtige, is sy tempel, en die Lam. En die stad het die son of die maan nie nodig om in hom te skyn nie, want die heerlikheid van God het hom verlig, en die Lam is sy lamp" (Openb. $21: 22,23$ ).

Die voleinding hou dus geen verberging of duisterheid in nie, maar ware godsdiens en sondelose liturgie, die bruilofsmaal van die Lam, die voltrekking van die heilige huwelik tussen Hom en sy Bruid. Hier is volk en kerk identies, want die ongelowiges verkeer in die buitenste duisternis. Hierdie volk is geen kosmopolitiese eendersheid nie, maar gevul met die heerlikheid van die nasies omdat die bevel van Christus in Matt. 28 : 19: „Maak dissipels van al die nasies..." vervul is. ${ }^{84}$

Een van die grootste probleme wat steeds dwarsdeur die geskiedenis van die liturgie na vore kom is die verhouding van Woord en Sakrament. 'n Ontginning van die rykdom en betekenis van die boek Openbaringe sal hier seker ryke vrugte afwerp. Die verhouding van Jesus Christus hang ten nouste saam met dié verhouding van Jesus Christus, die Vleesgeworde Woord, tot die geskrewe Woord. (Van belang is hierby die verhouding van tempel en sinagoge, en die vraag na hoeveel en wat van die seremoniële wet van die $\mathrm{Ou}$ Testament nog kan, mag en moet geld in die Nieu-Testamentiese Kerk. Die grondbeginsel hiervoor word duidelik gestel en bely in art. 25 van die Nederlandse Geloofsbelydenis.)

Ten slotte openbaar God in die laaste twee hoofstukke van Openbaringe die liturgies-volmaakte toestand na die oordeelsdag en gee hy ook ander interessante gegewens: die tempel van God (Hfst. $3: 12,11: 1,19,15: 5-8,16: 1$ ) verdwyn in die nuwe Jerusalem. Staan hierdie verdwyning nie in verband met die woorde van Jesus in Joh. $2: 19$ nie? Die tempel van klip sal afgebreek word, maar Hy sal opstaan na drie dae. Hierdie oprigting van die tempel, nl. van Jesus self, stem presies ooreen met Openb. $21: 22$. Dieselfde beginsels dat ' $n$ Mens die tempel van God is, vind ons ook in 1 Kor. $3: 16-23$, waar dit nie van Die Mens geld nie, maar van elke gelowige. Dit is eienaardig dat in Openbaringe net van die sinagoge van Satan gepraat word (Hfst. $2: 9$ en $3: 9$ ). Dit kan mens verstaan omdat die sinagoge eintlik later die aartsvyand van Christus en die Kerk geword het, maar dit gee ons tog ook 'n waarskuwing dat die Woord sonder die sakrament ook op duiwelswerk kan uitloop, en dikwels wel geword het. Verder leer ons ook in Openbaringe dat prag en praal ook godeverheerlikend kan wees, en nie altyd uit die bose is nie, soos menige Kwaker en Puritein dink.

\subsection{Die verbond van God}

\subsubsection{Erediens en ,"iturgie op straat" 88}

Tussen die skepping en die voleinding in die gang van die geskiedenis staan die mens in diens van God. God neem die inisiatief 
in die oprigting van die werkverbond met Adam. ${ }^{80} \mathrm{Lg}$. faal tragies en God neem weer die inisiatief en gee die tweede Adam, Jesus Christus. Vir Hom bly die verbond met God werkverbond, maar vir die uitverkorene word dit die genadeverbond, genade op grond van die verdienste, die volmaakte diens aan God, deur Christus. Hierdie liturgie van Hom word so heerlik en volledig beskryf en ontleed in Hebreërs en teenoor dié van Aaron gestel (vgl. ook die teenstelling Sara en Hagar, Gal. 4).

Die uitverkorenes is as Kerk die liggaam en bruid van Christus. Vir hulle beteken die genadeverbond vryheid en verlossing, maar juis daarom heerlike diens uit dankbaarheid, met die salige vooruitsig op die Bruilofsmaal van die Lam aan die einde van die dae. Die verbondsvolk dien en verwag onder leiding van die Heilige Gees die verheerlikte Christus. Daarom is dit honderd persent raak as veral Van Rongen (daar is ook ander) ${ }^{85}$ die liturgie van die Kerk sien as „De liturgie van Gods verbond". Hierdie dankbaarheidsdiens (vgl. Sondag 32 van die Heidelbergse Kategismus) dek die hele lewe van die gelowiges. Jonker noem dit "liturgie op straat". Tog kulimineer die diens op 'n besondere wyse in die erediens op Sondag, die dag van die Here, van die opstanding en van die weeroprigting van die Tempel van God (Joh. $2: 19$ ).

Om hierdie werk getrou en dankbaar te kan doen moet elke gemeente en elke gelowige hom steeds in sprekende gemeenskap met God bevind. Dit kan, mag en moet gebeur in die amp van die gelowige en in die erediens onder leiding van die besondere ampte. Dit is verbondsgemeenskap in die volle sin van die woord.

Ons moet hier net nog aandag gee aan die vorm van kerkisme, wat in die liturgie alles binne-in die kerk as instituut wil inhaal en hou. Ons meen dit is die geval met die Oosters-Ortodokse liturgie wat hemel en aarde en die hele heilsgeskiedenis in een erediens wil dramatiseer. Sommiges wil alle kuns, geleerdheid, en alles wat in God se skepping mooi is binne-in die kerkgebou en erediens saamdring. Die teoloog kan praat van kerk as instituut en as organisme (of van kerk en koninkryk, of nog iets beters). Die onderskeiding en eenheid moet ons albei handhaaf, en daarom ook die onderskeiding en eenheid van erediens en liturgie op straat. Orals moet die gelowige God eer en dien. Sy hele lewe moet erediens wees. Dit beteken nog nie dat al die vrugte van gehoorsaamheid aan die kultuurgebod (Gen. $1: 28$ ) in die kerk as instituut en veral in die erediens ingelyf word nie. Mooi konserte en Christelike drama's, verheffende mooi musiek en pragtige redenaarsretoriek, is alles erediens in ruimer $\sin$, maar nie in enger $\sin$ nie. ${ }^{87}$

Ter wille van ,liturgie op straat", op hierdie sondige aarde, waar die stryd van die eeue nog in volle gang is, moet die erediens dus sober wees, sober en nuttig soos die uniform van 'n werklike soldaat en die woorde en bevele van ' $n$ ware generaal. Dit kan ons beste en raakste formuleer as ons die erediens as amptelike verbondsgemeenskap van God met sy volk bepaal. Dit is 'n gespreksgemeenskap waarin God deur sy Woord en Gees tot die gemeente spreek, 
waarin hulle voorraad opneem en hulle sondes van die afgelope week bely en erken, sy seëninge tel, sy korreksies, vermaninge ontvang en weer nuwe bevele vir die komende stryd aanvaar. Daarom, as die kerk as gemeente nie bewus is van die stryd elke dag op straat en in eie huis en hart nie, dan is die krygsraad sinloos. As 'n sakeonderneming geen sake doen nie, dan word die vergadering van direksie-en-lede sinloos en vervelig. Baie duidelik sien ons dit telkens in die geskiedenis dat die martelaarskerk, die strydende kerk, geen probleme het met kerkbywoning en liturgiese apatie nie, want daar is 'n brandende honger na die vertroostende Woord, wat oproep tot stryd, gelei deur die Gees. As die kerk Laodicensies word, klaar gearriveer het, reeds nou al hom verbeel dat hy triomferende kerk is, dan help selfs geen viervoudige liturgiese beweging nie.

Erediens en liturgie op straat moet ook in verband gebring word met kerk en koninkryk. Die koninkryk is ook in die kerk. Die ekklesia, geroepe uitverkorenheid, is die gevolg van die sonde, maar tegelykertyd die vrug van God se liefde. As deel van die koninkryk wat is, indikatief, is die kerk in die verbond ook 'n verband, die verband van Gods volk, maar in die verband is die verbond die liefdesgemeenskap met God, wat sif en skei tussen koring en kaf binne-in die kerk, en na buite die instrument wat God gebruik om die wat nog in is nie in te bring. „Hierdie verband, die liggaam van Christus strewe in die verbond na sy volheid (na buite), asook na sy heiligheid (na binne, tug). Die kerk moet beide sentripetaal en sentrifugaal sending doen, ${ }^{88}$ en hiervoor en hiertoe moet sy liturgie ingerig wees en sy lidmate toerus en opskerp.

In die „Report on Worship”, „Fourth World Conference on Faith and order", 80 word die volgende vereistes vir die regte liturgie interessant soos volg gestel: eenheid sonder eendersheid, vryheid sonder kettery, ver-inheemsing sonder sinkretisme.

\subsubsection{Die seëls van die verbond}

By wat reeds oor Woord en sakrament gesê is, kan ons hier nou net stel dat die twee sakramente, wat deur die Reformasie as Skriftuurlik aanvaar is, ook in die allernouste verband staan met die verbond. Die doop is die teken van die inlywing in die verbond en die nagmaal is die verbondstafel, wat nie verontreinig mag word nie. Die liefdesgemeenskap tussen God en sy volk wat in die Woord hoorbaar is, kom hier sigbaar tot vergestalting.

Die instelling van die Ou-Testamentiese en hierdie tekens en seëls van die verbond val tussen Gen. 2 en Openb. 21, d.w.s. in die tyd van die sonde, toe die gemeenskap tussen God en die mense (selfs die gelowiges) ook verduister is. Daarom val die sakramente weg as die nuwe Jerusalem verlig word deur die heerlikheid van God. Hier vind nou die Bruilofsmaal van die Lam plaas, en diegene wat nie in die verbond ingelyf is nie en nie deel is van die liggaam van Christus nie, is saam met Satan in die buitenste duisternis. Die tug van die kerk, by die nagmaal, is hiervan 'n vooruitskaduwing (antw. 85 van die Heidelbergse Kategismus). Belangrik is hier dat 
Zwingli wat vier maal in die jaar nagmaal gehou het, dit gedoen het ter wille van die tug. Toe Calvyn verplig is om hierby in te val, het hy nog probeer om by die verskillende kerke in dieselfde stad die nagmaaldatums so te bepaal dat lidmate in staat sou wees om meer as vier keer nagmaal te hou per jaar, deur van die een kerkgebou na die ander te gaan. In die opsig lyk dit dus of Zwingli hier meer as Calvyn op die tug gesteld was."1

Terwyl die kerk aanvanklik dageliks en elke Sondag nagmaal gevier het, is dit 'n saak vir 'n aparte studie. Dit moet in verband gesien word met die feit dat die eerste gemeente die wederkoms van Christus min of meer onmiddellik verwag het. 'n Mens kan vra: Wat is die verband tussen die wederkoms, die bruilofsmaal van die Lam en die nagmaal? Is dit 'n regte of verkeerde ontwikkeling as die nagmaal minder as elke Sondag gehou word? Hang dit ook saam met die vraag of die kerk martelaarskerk of welvaartskerk is? Maak gevaar van buite die tug van binne eintlik in sekere sin minder nodig en omgekeerd?

\subsubsection{Verbondsonderwys. Liturgiek, pastoraal, homiletiek en kategetiek}

Von Allmen praat van ,education through liturgy". ${ }^{\text {so }}$ Hierteenoor word dikwels beweer dat die Dordtse liturgiese formuliere te eensydig didakties is. Luther het die didaktiese funksie van die liturgie sterk beklemtoon, maar tog was hy bedug vir die gevaar dat die ware godsdiens by die volwasse Christen deur die didaktiek versmoor kan word (vgl. 5.2.1.). Onkunde maak die lidmate werklik "leke", eintlik liturgiese „idiote"; te veel menslike didaktiek in die erediens maak hulle naderhand weer verveelde wegblyers van die erediens af. Tussen die twee gevare moet die kerk sy pad vind. Volwasse opvoeding buite die erediens deur geskrif en woord kan seker hier 'n groot gaping vul. Sover my bekend, word daar baie min, indien enige, aandag aan liturgiek in die katkisasie gegee. Gevolglik het die jong lidmaat belydenis afgelê maar nog nooit gesnap dat belydenis geen eenmalige gebeurtenis is nie, maar 'n gespreksgemeenskap met God wat daeliks en elke Sondag moet plaasvind. Elke lidmaat moet dus in die katkisasie volledig ook in die liturgie onderrig word. En die teologiese opleiding en wetenskaplike studie is in die kerk 'n behoorlike en volledige samewerking, tussen die bg. vier amptelike vakke absoluut noodsaaklik. Gesamentlike en afsonderlike studie van die openbaring van God in beide Skriftuur en natuur (geskiedenis) is brandend nodig, veral in ons tyd. Ons moet die Skrif ken en deurvors, maar ook die moderne gelowige in sy moderne tyd, nood, behoeftes, talente en roeping. Dit sal help dat daar meer volledige verbondsonderwys kom; kategese sal nie beperk word tot die teoretiese aspek van die leer nie, maar ook die liturgiese insluit; die preek sal nie net leer nie maar besiel tot behoorlike gemeentelike sang; ook in die pastorale moet die liturgie op die regte wyse ter sprake kom sodat dit onnodig sal word om van die erediens 'n skoolhouery te maak. 


\section{Toepassing. Die Gereformeerde Kerk in Suid-Afrika}

\subsection{Inleiding. „Gereformeerde" ver-heidensing?}

Ons glo dit is die suiwere Christelike metode om by die balk in eie oog te begin en die hand in eie boesem te steek. Ons wil nie hieroor die Gereformeerde Kerke in Suidelike Afrika nie (wat vier nasionale sinodes in een Algemene Sinode insluit) handel nie, maar slegs oor die Gereformeerde Kerk in Suid-Afrika.

Hierby aanvaar ons die goeie wat mag voorkom in ootmoed met dankbaarheid uit die hand van die Here en sê: „Nie aan ons, o Here, nie aan ons nie, maar aan u Naam gee eer..." (Ps. $115: 1$ ). Dit is God se goud wat Hy aan ons toevertrou het en wat ons daarom nie mag wegsmyt of in ' $n$ sweetdoek begrawe nie. ${ }^{01}$ Die slegte in dié kerk is van die sondige mens. Daar kan ook "Gereformeerde" ver-heidensing of paganisering (soos Nida dit noem) plaasvind. Sodra ons die hart van die kerk, die uitverkiesing uit loutere genade ${ }^{02}$ vergeet of verwaarloos, dan vergeet ons dat die ware godsdiens van God af kom en dan begin ons ons verbeel ons kan van onder af met God handel dryf. Dan kom ons as kerk voor God te staan in die gestalte van die hoogmoedige Fariseër en nie meer in die gestalte van die berouvolle tollenaar nie (Luk. 18:9-14). Dan is die dood in die pot en die einde naby.

\subsection{Die Gereformeerde Kerk is 'n 19 e eeuse ,afgeskeie" kerk}

Von Allmen sê: ,When the Church needs reformation, it is the cult that must be reformed". Hy praat ook van "education through liturgy". ${ }^{3}$ Dit is wat die Gereformeerde vaders in 1859 o.a. probeer doen het. Daarom vind ons by hierdie „Nadere reformasie” (soos Algra dit noem) totale liturgiese herbelewing in 'n konserwatiewe teruggryp op Dordt, soos reeds genoem, en geen moderne liturgiese vernuwing soos in die Liturgiese Beweging nie. By wat ons reeds in 5.3.4. gesê het om aan te toon dat die kerk glad nie liturgies verstar het vanaf 1859 nie, moet ons hier twee puntjies byvoeg: i) Net soos Dordt konfessioneel voortgebou het op die destyds bestaande konfessies en dit uitgebou het tot die Drie Formuliere van Enigheid, moet ons ook vorentoe kyk en voortbou waar nodig, ook liturgies en wel in allerintiemste verband met die belydenis. Dit is 'n delikate en groot saak wat ook uiteindelik genadig van God moet kom, maar waarby ons as kerk, saam met ander Gereformeerde Kerke, nie ons plig mag versaak nie. ii) Ons moet die liturgiegeskiedenis baie deeglik bestudeer sodat ons nie daarin verval om skoppelmaai te ry in ons sinodebesluite oor liturgie nie. Dit verwar die lidmate, ondermyn die aansien van die kerk en werk liturgiese apatie en verlamming in die hand, as die een vergadering telkens die besluite van 'n vorige een moet verduidelik of vervang. ${ }^{94}$

Die liturgie kan slegs groei en ontplooi in die rigting van Openb. 21 en 22 as die leer groei en ontplooi, anders kry ons 'n massiewe ,natuurlike" opeenhoping van mooi, helaas, dikwels dooie, dinge in die Kerk (vgl. 5.3.1., eerste paragraaf). 


\subsection{Die Gereformeerde Kerk is uiters klein, gewoond om in klein gemeentetjies in diaspora te leef}

In dié opsig is die kerk al honderd jaar modern. Algra beskryf die wonder van die negentiende eeu in die kerklike ontwikkeling deur klein mensies in klein gemeentes baie treffend. ${ }^{05}$ Soos reeds aangedui is dit juis wat die moderne mens na smag omdat hy verdwyn en vergaan in die moderne groot stede en groot organisasies. Die waarheid van die plaaslike kerk as volledige openbaring, hoewel nie allenig die enigste nie, van die liggaam van Christus is net wat die mens vandag nodig het om sy kleingroepbehoefte te bevredig en te vul met die heerlikheid van God deur sy Woord en Gees.

Deur hulle besonder klein gemeentes in groter gemeenskappe het die Gereformeerdes al heelwat ondervinding opgedoen daarvan om in diaspora te leef, en te getuig ${ }^{91}$ (vgl. 5.5. hierbo). Die amp van die gelowige, die ontplooiing van die gewone man en vrou vind geen beter teelaarde as 'n klein gemeentetjie nie, daar waar hulle heel gou moet help werk, regeer en selfs leesdiens hou. (Dit is interessant dat die leesdiens geen moderne Gereformeerde uitvinding is nie, maar reeds al in die Middeleeue voorkom. ${ }^{\text {"1 }}$

\subsection{Tugloosheid versmoor die kerk}

Met al hulle swakhede en tekortkominge aanvaar die Gereformeerdes nog altyd dat daar drie ewewaardige kenmerke van die ware kerk is, nl. soos in art. 29 van die Nederlandse Geloofsbelydenis bely. Hierdie staan hulle teenoor ander wat net die eerste twee aanvaar as grondleggend, nl. suiwere bediening van die Woord en van die sakramente. ${ }^{97}$

Het ons nie in lg. die wortel van die kwaad in die reeds genoemde valse en dodelike teenstelling van Woord en sakrament nie? Al sou ons soos Golterman e.a. hierdie teenstelling wil vermy en oorbrug deur te praat van 'n ellips, ${ }^{08}$ dan bly dit nog 'n gesukkel en aanleiding tot oneindige en onbevredigende debatte, net soos in die Ooste (soos dit gestel word deur Bavinck in 5.3.1. hierbo), daar steeds 'n eienaardige dualisme voortwoeker tussen ortodoksie en mistisisme. Ook hier kom dit finaliter neer op die handhawing en uitbou van die Drie-eenheidsleer. Soos daar in die een God drie Persone is, is daar in die erediens drie elemente, en nie net twee nie. Hoedat dit presies uitgewerk en toegepas moet word kan ons nie nou hier gee nie, maar wel kan ons stel dat ons die liturgie nie mag losmaak van die sleutels van die hemelryk nie, d.w.s. van die tug nie. Beide Woord en sakrament sluit oop en toe, maar by e.g. doen God Self, God die Heilige Gees die toepassing (daarom bly die kerkdeur oop vir alle sondaars), by lg. het die Kerk, die gemeente in die ampte ' $n$ heilige en gevaarlike taak in die hantering van die ban (vgl. vrae en antwoorde 81-85 van die Kategismus).

Die erediens sluit nie in 'n bepaalde gebou met sy majestueuse skoonheid en aangrypende ritusse, soos in die Ortodokse kerke, die hemel vir die mens oop nie, maar slegs deur die lewende verkondiging van die Woord. By die bepaling van die aantal kere wat 
die nagmaal gevier sal word, moet die kerk, soos reeds aangedui, nie uit die oog verloor dat die onthouding van die nagmaal af die ,wapen van tug" is, wat uiteindelik mag uitloop op die ban. Sonder hierdie "geleidelike" wapen ontaard die ban tot staatsstraf en gaan die geestelike, pastorale element van die tug verlore.

Die mens se volle gemeenskap met God word ook nie bewerkstellig nie deur die hoogtepunt van die eucharistie van die RoomsKatolieke Kerk nie, maar in die daelikse wandel met of sonder God, in die waaragtige bekering wat onder leiding van die Heilige Gees 'n afsterwing van die ou mens en 'n opstanding van die nuwe mens is. Die liturgie, in die drie elemente van Woord, sakramente en tug, moet die gelowige wapen tot die stryd (Ef. 6), en hom steeds meer en voller en ryker 'n tempel van God die Heilige Gees maak (1 Kor. 3).

In swakheid het die Gereformeerdes nog altyd hierdie vorm van tug gehandhaaf, en daarmee die liturgie wakker gehou, d.w.s. waar ook in liefde tug toegepas is op diegene wat die vierde gebod oortree deur nooit kerk toe te kom nie.

Hiermee is ten minste nie die basis prys gegee van 'n volledige uitwerking van die verband tussen die goddelike Drie-Eenheid en genoemde liturgiese drie-eenheid nie.

\subsection{Die Gereformeerde Kerk het die nodige kerklike apparaat vir twintigste eeuse liturgiese voortbou}

Waar die één groot „talent” van die Gereformeerdes die handhawing van die plaaslike kerk as volledige openbaring van die liggaam van Christus is, is egter nie die ander kerke uit die oog verloor nie. In die Gereformeerde Ekumeniese Sinode, wat wel geen gesaghebbende meerdere vergadering is nie, het die Nasionale Sinode saam met die Nederduits Gereformeerde Kerk in Suidelike Afrika, tog 'n gespreksgemeenskap met Gereformeerdes oor die hele wêreld en onder allerlei volke en tale. In die eie Algemene Sinode, wat as vyfde kerklike vergadering die vier nasionale sinodes van die verskillende tale en volke insluit, het ons 'n meerdere vergadering, waarop beide eenheid en verskeidenheid in die één kerkverband institutêr tot vergestalting en in werking kom. Die uiteindelike twintigste eeuse voortbou van die liturgie, in sy eenheid en verskeidenheid van ver-inheemsing, moet hier plaasvind en sy beslag kry.

Ons sluit met opset af met liturgiese voortbou en nie vernuwing nie, omdat lg. woord die gedagte wek van veroudering. Die ware liturgie gebou op die Woord van God en gelei deur die Heilige Gees kan nooit verouder nie. Deur die sonde van die mens in die kerk kan dit wel ontaard, versand of totaal stagneer. Daarom is Skriftuurlike uit- en voortbou onder leiding van die Heilige Gees taak en roeping. Dit is egter iets wat nie maklik kan slaag so lank as wat die kerk leef in 'n eb van die werking van die Heilige Gees nie. Dit word dan lapwerk. Met koue yster kan mens nie sweis nie. As die Kerk weer vloeibaar warm word, pletbare 
staal, deur die krag van Woord en Gees, sal dit wat nuut mag wees bestendig ingesweis kan word in die goeie en ware wat reeds is totdat $\mathrm{Hy}$ kom en die nuwe Jerusalem van God neerdaal op die nuwe aarde.

Prof. dr. D. C. S. van der Merwe, Potchefstroom.

79 G. G. Z. Seerveld e.a.: , Out of Concern for the Church", Wedge Publ. Foundation, Chicago, 1970, p. 48.

80 J. H. Bavinck, red.: „De Heilige Geest”, Kok, Kampen, 1949, p. 439.

81 D. G. Delling: „Worship in the N.T.", Londen, 1962, p. xii; C. F. D. Moule: "Worship", Lutterworth, Londen, 1961, p. 13; R. Stälin in a.w., by 18, p. 8 .

82 E. A. Nida: „Religion across Cultures”, Harper \& Row, Londen 1968, p. 81.

83 J. L. Helberg in a.w. onder 13, asook in ongepubliseerde kollegediktate.

84 J. C. Coetzee: „Volk en Godsvolk in die N.T.”, Pro Rege, 1965.

85 G. Ran Rongen: „De Liturg:e van Gods Verbond”, Vuurbaak, Groningen, 1968.

86 H. Jonker: a.w., p. 136.

87 „De viering van de Zondag ,Laetare"”, Philips, Plaat no. G03455 L, wat 'n sg. liturgiese diens gee, lyk o.i. meer op 'n gewyde „konsert". Konserthou pas na die week se werk, ook eenmaal na die eeue se werk in die nuwe Jerusalem op verhewe-heilige wyse, maar die erediens op die dag van die Here, eerste dag van die week, is krygsraad, direksie-enlede-vergadering of spanpraatjie, gedeeltelik met die oog op die werk en wedstryd van die week wat voorle ( 1 Kor. $9: 24-26$ ).

88 „Sending en Verbond" (sien 69), pp. 315-342.

89 Faith and Order, Paper no. 39, W.C.C., Geneva, 1963, p. 41.

90 J. J. von Allmen: „Worship; its theology and practice", Lutterworth, Londen, 1968, p. 312.

91 D. C. S. van der Merwe: „Die roeping tot Gereformeerde getuienis”, in: „In die Skriflig", Sept. 1971, jg. 5, no. 19, p. 45 en verder.

92 D. C. S. van der Merwe: „Sending en Uitverkiesing", Potchefstroom, 1960.

93 Von Allmen: a.w., p. 53, 312-314.

$94 \mathrm{Bv}$. in verband met die plek van die kollekte in die erediens, Acta 1964, pp. 477-490; twee nagmaalvierings op een Sondag in dieselfde gemeente, Acta 1967, pp. 162-165, asook Acta 1970, pp. 167-174; sing al dan nie na belydenis van geloof, Acta 1973 en Acta 1964, p. 530.

95 Algra vertel van 'n gemeentetjie van 9 lede, waarvan slegs drie kon lees, a.w., p. 134.

96 C. C. de Bruin in: „Handboek der kerkgeschiedenis”, II, p. 47 en 50 . Of dit presies dieselfde is as 'n Geref. leesdiens, is 'n oop vraag.

97 A. Moorrees: „Die N.G. Kerk in S.A. 1652-1873", S. A. Bybelver., Kaapstad, p. 855, vgl. ook A. G. Honig hieroor in: "Handboek der Geref. Dogmatiek", Kok, Kampen, p, 723 e.v. oor die kwessie van twee of drie (of selfs een) kenmerke van die ware kerk.

Golterman: a.w., p. 71 . 